INFORMATION STUDIES DAYS 2020

\title{
Developing user-centered research services at the National Library of Finland
}

\author{
Liisa Näpärä \\ National library, University of Helsinki \\ liisa.napara@helsinki.fi \\ https://orcid.org/0000-0002-6473-5896
}

Keywords: library labs, development projects, research

\section{Introduction}

After digitalization and data mining possibilities there has been an emerging demand for new kinds of library services (Saarti 2019, 11). These new services require careful design, marketing, communication, personnel and system development (Shen \& Varvel 2013, 553). There is an essential need for more structured research services also at the National Library of Finland. In order to develop our research services, the Digital Open Memory project is collecting

This article is licensed under the terms of the CC BY-NC-SA 4.0 -license

Persistent identifier: https://doi.org/10.23978/inf.99082 
and analyzing data in close research collaboration. The project is financed by the European Regional Development Fund Leverage from the EU 2014-2020.

In the project, we conducted a survey targeted to researchers and later interviewed them. We also participated in research collaboration and funding application processes together with researchers from Universities of Turku and Tampere. Additionally, we benchmarked many European data-driven research services to find out what other national libraries have done in researcher collaboration with digital humanities researchers.

\section{The survey about digital resources and services of the National Library}

The research survey about digital resources and services of the National Library was conducted in spring 2020. There were 130 respondents in total, in Finnish, Swedish and English. Most of them were Finnish researchers. The survey asked about researchers' experiences and developing ideas for the digital resources and services. The survey was designed with the research process and data management plan (DMP) in mind. The survey asked which services need to be improved and what the National Library should focus on more in its digital collection development.

The survey results showed that researchers mostly use historical newspapers on their own computer. The respondents pointed out that, due to the copyright issues and still ongoing digitization process, there is not enough digital research material and access to it needs to be improved. They proposed some technical developments for the user interface. They also suggested that information about available digital resources and services should be clearer and more transparent. Furthermore, research collaboration should be easier and more straightforward.

In the survey, the respondents were asked to give their contact information, and about one third of them did. After analyzing the survey results our project planned interview questions that followed the themes 1) digital resources and their technical development and 2) digital resources and research collaboration with the National Library. About 20 researchers participated in the interviews. 


\section{Collaboration with the researchers}

Besides the survey respondents we interviewed researchers with whom we have or have had research collaboration already. The National Library has participated in several research projects such as COMHIS and Translocalis. The role has varied between a data provider and an active researcher companion with co-authorship. The current development project enhances collaboration with researchers. The aim is to focus more closely on the mutual benefits of research projects than before.

In the project the research collaboration between the National Library and researchers is observed. According to Andrew Crabtree and his fellow researcher (2012) companions the ethnographers', as well as anthropologists', duty is to explicate and make practices of real life visible. As Crabtree et al. are suggesting that any ethnographer's role is to go and look and even participate in what people actually do, and in the places where something actually happens. (Crabtree 2012, 3, 39.) It is the basis of anthropological fieldwork, even though ethnography takes place in this project mostly online.

After the participant observation of researcher collaboration, there is still need for discussion with collaborative participants and reflection in how the research collaboration can be improved in the future. The results are combined with the benchmarking results from the other European data-driven research services. Together with all data, the model for data-driven research services is planned and services are established in a more structured way after that.

\section{References}

COMHIS. https://wWw.kansalliskirjasto.fi/en/projects/comhis-computational-history-andthe-transformation-of-public-discourse-in-finland-1640

Crabtree, A., Rouncefield, M., \& Tolmie, P. (2012). Doing Design Ethnography. London: Springer. https://doi.org/10.1007/978-1-4471-2726-0

Shen, Y. \& Varvel, V. E. (2013) Developing Data Management Services at the Johns Hopkins University. The Journal of Academic Librarianship, 39(6), 552-557. https://doi. org/10.1016/j.acalib.2013.06.002

Translocalis. https://research.uta.fi/hex/translocalis/ 